\title{
高举紅旗 大搞水利电力事業
}

\author{
張 含 英
}

(中国水利学会理事長)

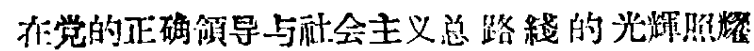

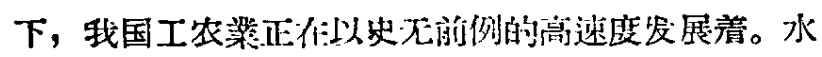
利建設采取了全面規划、綵合治理、以蓄为主、以小 型为主、以耐办为主、中资与地方扑举、人中小抹 举、士洋扭举、兴利与除害相絬命、治标与洽本相絬 合的方針，发捛了全国人民的干勁，便水利运动在全 国声势浩大地开展起来, 工程进屡的速度和規模的宏 偉是十分惊人的。

从去年十月到今年比月底, 佂水利工程方面, 全 国共完成士工和石工总量 560 多亿立方公尺, 相当于 修筑長城 373 座。灌溉面积由 5 亿 2 千万亩，扩大到 9 亿 7 千万亩，佔妌地面积的 $58 \%$ 。新增加的灌㳊面 积相当于解放前原有灌袥面积的雨倍, 師不到一年, 所做的工程等于过歨几千年的网倍。不少地区已經基 本上笑現了水利化，为今年的农等大丰收提供了有力 的保証。电力工業, 1957 年底, 裝机容量已經超过 解放前的一倍多，年发电量超过解放前最高年分的 2.25 倍。队河航运里程, 在 1957 年郎較解放初期增 加一倍, 內河航运量以吨公里訫, 1957 年較 1950 年 增加兩倍多。海运也有很大发展。至于防御洪水的能 力, 則已大为加强。以今年的黄河洪水而論, 挈厂 (郑州鉄桥以西) 洪等流量达到 21,000 秒立方公尺, 与 1933 年相似, 无論就这次洪等与洪量来說, 均相 当于一百年一遇的洪水, 但經大力的防护下, 抹水箱 用分洪措施, 安然下洩。

但是, 由于工农栗的迅速发展, 对于水利建钤的 要求也就更为迫切。我們的目标是: 三年水利化，五 年电气化, 以达到大雨不成災, 不雨保丰收, 和电力 工絜做到名符其实的先行工慗的要求。所以第二个五 年的㡽設任务是非常繁重的。

要完成这样巨大的任务, 我们是有信心的, 主要

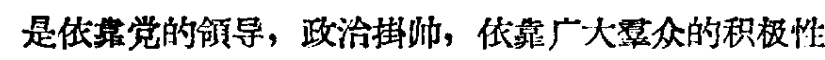
和刢造性, 低靠地方的力量, 依靠全民一齐动手。另 一方面要打破迷信, 解放思想, 开展科学研究, 晋及 科学技术, 掀起技术革命。

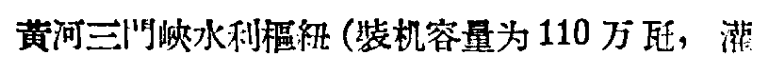

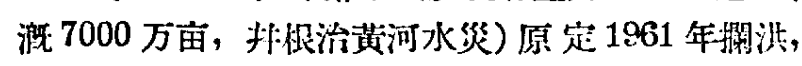
1962 年完成, 現任預計提囬门一年攔洪, 提前 牛年发

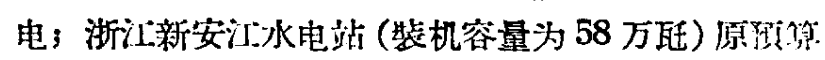
4 亿多元, 經精打細算后, 可以减少 1 亿多元的投

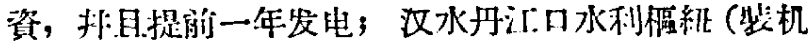
参量 70 万狂, 灌溉 1200 万亩, 抹根治汉水水災) 提 前于今年开工，預言卜在: 1961 年建成; 浯河刘芜峽水

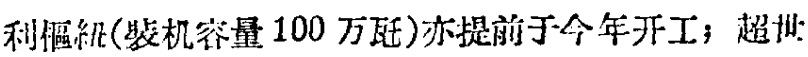
界水分的辰江三峽梠䊼工程, 正在积极准备。这个工 程罚学約 200 公尺, 蓄水 600 亿立力分尺, 工程量极

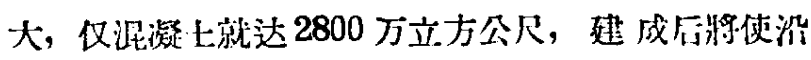
汇平原防洪状况发生根本的变化。三峽水电站裝机容 量將为 2,200 万瓦, 年发电量 1 千多亿度。这个工秙 將等取提前开工。

全国各地都准备今冬朋春报起一个更大的水利高 潮。例如河南省，今年已經使 $89.5 \%$ 的耕地有了灌 激殷备, 抹目保証了在一次降雨 200 公厘时, 尔取一 次降雨在 300 到 500 公厘时, 在山区做到士.不下山, 水不H!川，位本原地区做到就地攔蓄。又訃划今冬明 春沙繼結开展一个規模更大，进度更快，質量更奶的 水利建毁运动。在䋊續兴修小型工程的同时, 大力修 建中型工程和必要的大型工程, 以达到根本消灭水早 災害和符合利用水利資源的目的。訃划完成大型水庫 7 座, 蓄水 500 万战方公尺以上的中型水庫 400 座, 以及大量的河网渠道工程, 总計士工、石工約 350 亿 立方公尺。这只是全国各地雄偉計划的一斑。据估 計, 今冬明春全国土工、石工的总量將在 1200 亿立。 方公尺以上。可以想象, 全国水利事輩是怎样的迅速 发展着, 全国的面貎是怎样的迅速变化着!

我们的邧:会主义貄殿要求高速度地发展科学技 术。为了完成今后夏为复杂的水利建設任务, 就要求 水利科学技术有更一的织进, 要来一个技术革命。仨 生产实践的过程中，在学习苏联和世界其他国家的先 进經驗中, 位总絬我国旧有的經驗中, 我們的科学技 术虽然有所提高，但是，却还远不足以滿足生产的需 要，为了迎接更大的任务，必須快默师鞭，飞跃发 展，

科学技术的发展应当是提高与普及相絬合。科学 技术是为形会主义建颜服务的, 既需要提高, 比需要

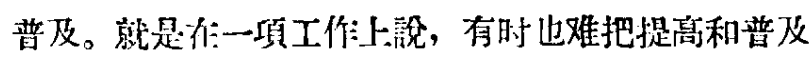
分开。例如, 我們正位根据需要, 大力修建中型水

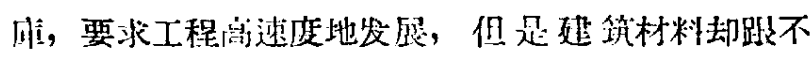
.上, 就必須研究代川品。为了适应扠速建版, 也要䂰

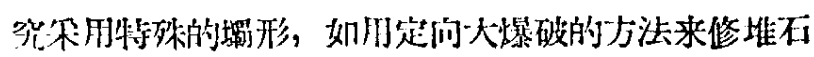


欮。为了能提前完工, 还希些能住雨季和冬季施工。 諸如此类的問題很多, 解决这些問題, 就有賴于技术 革新, 萢驗研究。但是这些工作究竞屬于提高呢, 还

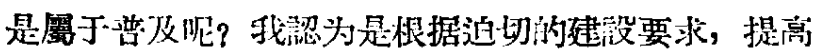
技术, 扑把它惊推广使用, 只要一有創造, 就全面地 朵用。虽然在某些工作方面, 提高与普及可以分工办 理, 但为了滿足生产要求的目的, 二者則必須是互相 結合的。

这里率涉到一个恨朴問題, 就是科学技术必須为 生产服务, 必須为社会主义建設服务。在这样的要求 下，提高与普及必須是互相結合的。

所以在水利科学技术发展方面，一是解决像長江:

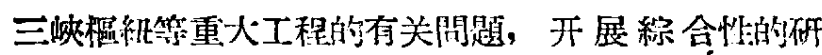
穴, 发展水利技术中的尖端科学, 帶动一切; 一是解

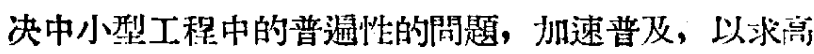
速度地发展水利建設。

男一个根本閣題是科学工作和技术革命低靠誰的

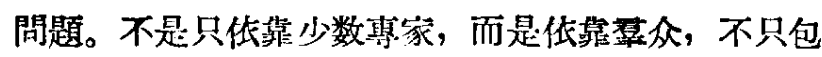
括勘測、䂴計、施工、生产方面的干部，而且包括工

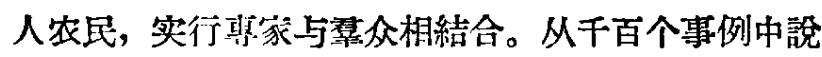
明，技术革新的紹大部分，都是工人、农民和文化水 平較低的技术干部刢造出来的。所以技术革命和其他 的工作一样, 必須走䐆众路綫。

随着耐会主义建設的蓬勃发展, 科学技术也获得 了巨大的发展, 它为完成建竑任务提供了有力的保 证。这一方面表現在㗪众的大量刢造发朋, 很多工人 农民出身的專家在各地都起了总工程师的作用。另一 方面表現伿各地方科学技术力量的增長，他們已經完 成、抹目正在修建很多大、中型的工程，甘㴋省永站 县的英姚渠, 有一个跨过黄河的拱形木渡槽, 是由初 中二年級欵業、部队轉業、26岁的陶維民同志設計 的。这个設計經过㗱众討論, 由于化錢少, 施工快, 被采用了。而另一个鋼絲吊桥式渡槽钤計則被放率 了。甘肃省嘉略关西的白偒河引水工程, 翠众創造了 17 公里榢道的奇跡。这个渠道引水 3 秒立方公尺。 豚道还有三㢈倒第河满的虹。吸, 最宽的河清 290 公 尺, 最深的 36 公尺。河北省涉县的滰北大渠, 全長 90 公里, 不工就有 85 万立方公尺, 有石洞 12 个, 士洞 16 个, 共辰約 5.5 公里。需要鑽通断头崖, 糪 开圣佛山, 砍断老虎头, 搬倒风鳳山, 这些都是很大 的險工。在党的領导和翠众的冲天干勁下, 三年計 划, 十个月就完成了。湖北省随县的鞍山軍民合作水

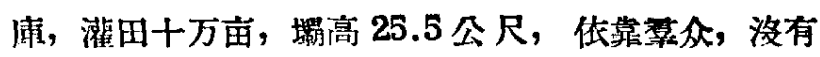
一个工程师, 在 154 天內完成了, 开支 40 万元, 其 中一牛是国家投資, 一牛是翠众自筹。这个工程, 根 据“老經驗”要花二三百万元。在基众的㓣造发明下， 垎省举办的工程也有很大的发展。例如, 湖南省近年 修建了喵处輕型混凝土罚, 高度均在 40 公 尺以、t,
节行了大量的水泥。河北少就地取枌，修建一些中型

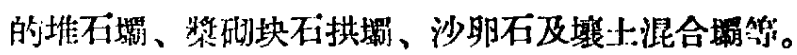
今年水利事掌的大跃进，是的于賁彻了“三主”的方

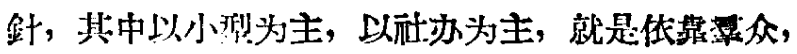
依靠众解决了各种困难, 包括技术上的成难, 才筷 得这样大的成就。这些事例是說不完的。在最近水利 电力部和中国水利学会联合召开的全国中型水利水电 工程經驗交流会議上，提们了二百多篇冈容丰䇺多尔

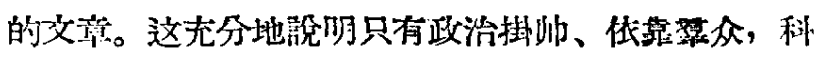
学技术才能大跃进, 才能解决生产上的問題, 才能多 快好省地完成建設的任:务。

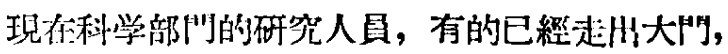
面向生产, 这是好的, 是问前迈进了一步。但是, 有 的却还只是工作形式上的轉变, 在研究的方法和队客 上, 仍然是結合生产不够, 翠众看到研究的成果后 說: 这个办法很奵, 但是我們不能使用。这里我想就 另外的网个例子說一下。在上述的会議上, 有一筒介 紛草士混合蜀的报告和一篇介紹水中倒士筑羁的报 告, 是經驗介紓中最受欢迎的一部分。草土混合罣就 是黃河，所用的增工，是我国劳动人民几千年来的遺 产，在㣴河流域及其他地区都广泛使用。1956 年在: 䉒州自来水厂黃河进水口上, 使用这种方法筑成施工 圍堤, 成功地解决了阻水导流問題,比原来国外殷計的 施工方案, 縮短工期 70\%，节約工費 76\%，还避急 了很多技术裝备和物資供应上的困难。正在施工的黄

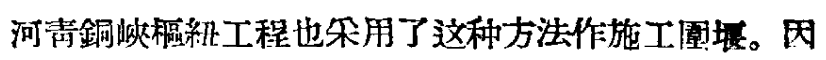
为这种方法所使用的材料, 只是些麦草、积草、蕰武 或高梁管, 也有用树梢的, 如楖枝等, 此外, 就是一些

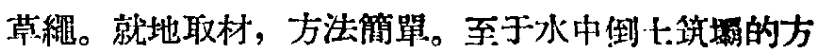
法, 本是学习茨联的經驗, 在我国川西劣沁县月领川 水庫初次应用, 获得良好效梁。我国不少地区也就有 类似的施工方法。这种施工方法, 不需㜊压, 施工进

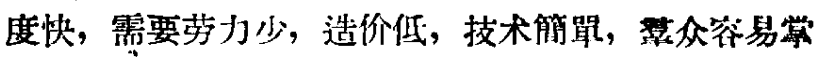
搌, 所以受到欢迎。上边所說的英雄渠上网个渡槽設 計的取舍, 也說哬这个道理。研究工作，不仅要走出 大朋, 还要适应当前的跃进形势, 解決迫切需要的笑

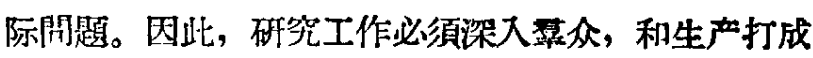
一片, 同劳动人民共呼吸, 扸研究川更为有用的东 阮。这样，不只提高了技术，同时，通过生产的实 践, 也便于进行思想改造。

总之，促进技术革命，首先要加强党的領导，坚 持政洽掛帅，坚决依靠瑟众，面向生产，緹合实际， 破除迷信，解放思想。从事科学技术工作的盗产阶极 知識分子龙应在生产实践和劳动中改造思想、提高技 木, 才能充分发挥力量。

讓我們在党的领导下，在总路綫的光辉照耀下， 破除迷信，解放思想，开展技术革命的壆众运动，为 建毁矿会主义而奋斗。 